\title{
Relationship between microstructure evolution and tensile properties of AlSi10Mg alloys with varying solidification cooling rates
}

\author{
Maressa Gandolfi ${ }^{1}$, Marcella Gautê Cavalcante Xavier ${ }^{1}$, Leonardo Fernandes Gomes ${ }^{1}$, Rodrigo André \\ Valenzuela Reyes ${ }^{1}$, Amauri Garcia ${ }^{2}$, José Eduardo Spinelli 1,3,*
}

\footnotetext{
${ }^{1}$ Federal University of São Carlos, Graduate Program in Materials Science and Engineering, 13565-905 - São Carlos, SP, Brazil. 2 Department of Manufacturing and Materials Engineering, University of Campinas, UNICAMP, 13083-860 - Campinas, SP, Brazil. ${ }^{3}$ Department of Materials Engineering, Federal University of São Carlos, São Carlos, SP, 13565-905, Brazil.
}

\begin{abstract}
.
This work explored and contrasted the effect of microstructure on the tensile properties of AlSi10Mg alloys generated by transient directional solidification depending on variations in cooling rate and Magnesium $(\mathrm{Mg})$ content (i.e., 0.45 and $1 \mathrm{wt} . \% \mathrm{Mg}$ ), with a focus on understanding the dendritic growth and phases constitution. Optical and Scanning electron (SEM) microscopies, CALPHAD and thermal analysis were used to describe the microstructure, forming phases and resulting tensile properties. The findings showed that the experimental evolution of the primary dendritic spacing is very similar when both directionally solidified (DS) Al-10wt.\% Si0.45wt.\% Mg and Al-10wt.\% Si-1wt.\% Mg alloys samples are compared. The secondary dendritic spacing was lower for the alloy with more $\mathrm{Mg}$, especially considering the range of high growth velocities. Moreover, a greater fraction of $\left(\mathrm{Al}+\mathrm{Si}+\mathrm{Mg}_{2} \mathrm{Si}\right)$ ternary eutectic islands surrounding the $\alpha$-Al dendritic matrix was noted for the alloy with $1 \mathrm{wt} . \% \mathrm{Mg}$. As a result of primary dendritic spacings greater than $180 \mu \mathrm{m}$ related to lower cooling rates, slightly higher tensile properties were attained for the Al-10wt.\% Si-0.45wt.\% $\mathrm{Mg}$ alloy. In contrast, combining dendritic refining $(<150 \mu \mathrm{m})$ and larger $\mathrm{Mg}_{2} \mathrm{Si}$ fraction, fast solidified DS Al-10wt.\% Si-1wt.\% Mg samples exhibited higher tensile strength and elongation. The control of cooling rate and fineness of the dendritic array provided a new insight related to the addition of $\mathrm{Mg}$ in slightly higher levels than conventional ones, capable of achieving a better balance of tensile properties in AlSi10Mg alloys.
\end{abstract}

Keywords: AlSi10Mg alloys, solidification, thermal analysis, microstructure, tensile properties.

(*) Corresponding author

E-mail address: spinelli@ufscar.br, Tel. ++55 16 3351-8512 


\section{Introduction}

Even though the AlSi10Mg (Al-10wt.\% Si-Mg) alloys may be processed in a variety of techniques (i.e., additive manufacturing - AM, high pressure die casting - HPD, and permanent mold casting - PM, among others), a better understanding of the solidification cooling rate effects on the microstructure and mechanical properties remains a task to be achieved. Although there is a reasonable amount of research carried out on AlSi10Mg alloys, no study was found with the focus on determining the solidification rates in an expressive range in order to comprehend the influence of this thermal parameter. Then, the main studies and their findings will be reported next, demonstrating processing and microstructure aspects regarding to the AlSi10Mg alloys.

PM casting processes - unlike HPD which is carried out by injecting the molten metal into a mold at high speed, high cooling rates $\left(10^{1}-10^{2}{ }^{\circ} \mathrm{C} / \mathrm{s}\right)$ and high pressure - are performed under the effect of gravity. In this case, the molten metal enters the mold at low speeds and solidifies at lower cooling rates $\left(<10^{1}{ }^{\circ} \mathrm{C} / \mathrm{s}\right)$. Regarding the microstructural analysis carried out by Zhang et al. [1] for Al-10Si-0.6Mg samples solidified by HPD, it was observed the formation of an outermost layer containing $\alpha$ - $\mathrm{Al}$ dendrites enveloped by the $(\mathrm{Al}+\mathrm{Si})$ eutectic, a sub-layer rich in eutectic and another sub-layer rich in $\alpha$-Al dendrites [2,3]. Dendrite length-scale size also changed becoming coarser towards the center of the sample. This was attributed to the changes in cooling rate, which are quite higher for positions closer to the mold walls. After the formation of these surface layers $(\sim 180$ $200 \mu \mathrm{m}$ thick), the microstructure becomes more uniform and coarser. As expected, the average secondary dendritic spacing, $\lambda_{2}$, of the PM samples was greater than that observed in the HPD samples due to the lower cooling rates [1]. Moreover, the eutectic $\mathrm{Si}$ and the $\mathrm{Mg}_{2} \mathrm{Si}$ phase in the PM sample were larger in size than in the HPD sample.

Yan and coauthors [4] investigated the influence of microstructure features on the mechanical properties of the AlSi10Mg alloy manufactured by conventional casting $\left(10^{0}-10^{1}{ }^{\circ} \mathrm{C} / \mathrm{s}\right)$ compared with that same alloy manufactured by selective laser fusion (SLM: $10^{3}-10^{6}{ }^{\circ} \mathrm{C} / \mathrm{s}$ ), with an emphasis on understanding the mechanisms of formation of the microstructure. Large differences in performance were observed between the as-cast sample and the SLM sample. The SLM sample had anisotropy in 
relation to the tensile properties, but it also had more refined grains and different precipitated phases, which also led to increased tensile strength for loading conditions perpendicular to the grains alignment direction. In contrast, loads in the parallel direction in relation to that of the grains alignment provided lower values. On the whole, as a result of grain refinement and a tortuous crack course, the SLM AlSi10Mg sample showed higher tensile strength but lower elongation than the ascast sample.

In the assessment of slightly higher $\mathrm{Si}$ levels, Kakitani and coauthors [5] investigated solidification features of the $\mathrm{Al}-15 \mathrm{wt} . \% \mathrm{Si}-1.5 \mathrm{wt} . \% \mathrm{Mg}$ alloy. It was demonstrated that dendrite interphase spacing measurements agreed with Hall-Petch calculations for ultimate tensile strength and elongation to fracture considering a broad range of cooling rates. It was demonstrated that controlling the distance between the ductile $\alpha$-Al phase as well as the eutectic strengthening constituent is essential since it affects the alloy's tensile properties. As the dendrite interphase spacing was shortened, remarkable increases in strength and ductility were attained. Studies evaluating dendritic growth in Aluminum (Al) alloys and factors influencing this growth as well as consequences on the application properties are prominent in the specialized literature [6-13].

Marola et al. [14] found a connection between the microstructure, phase constitution, and thermal behavior of AlSi10Mg samples generated using different rapid and intermediate solidification techniques. The wider and lower the reflections become as the cooling rate increases, indicating increased supersaturation and smaller grain size. However, neither the values of the cooling rates have been determined nor their direct interrelationships with microstructural parameters such as $\lambda_{2}$, for instance.

Pereira and collaborators [15] performed a comparison of the microstructures and mechanical properties of the $\mathrm{Al}-7 \% \mathrm{Si}-0.6 \% \mathrm{Mg}$ alloy obtained through SLM and lost wax (LW) casting. Regarding the microstructure of the generated samples, it was noted that the SLM sample was composed of a thin cellular structure having $\alpha$-Al cells smaller than $1 \mu \mathrm{m}$ in size and with eutectic $\mathrm{Si}$ and $\mathrm{Mg}_{2} \mathrm{Si}$ grouped in the intercellular regions. In the LW sample, the microstructure was composed of the $\alpha$-Al dendritic matrix, eutectic Si and $\beta$ Fe-bearing intermetallic particles. 
Recent studies by Arici et al. [16,17] have evaluated both the microstructure and the mechanical properties of $\mathrm{Al}$ alloys containing high Silicon $(\mathrm{Si})$ and low $\mathrm{Mg}$ in their compositions. These studies focused on the impact of minor additions of transition elements such as Zirconium $(\mathrm{Zr})$, Vanadium (V), Titanium (Ti) on the properties of these $\mathrm{Al}$ alloys. One of the chosen alloys was the Al-10wt.\% Si-0.3wt.\% Mg for melting in PM casting. Manganese (Mn) was added to reduce the tendency of the alloy to react with the mold. The resulting microstructures showed dendritic growth and formation of eutectic $(\mathrm{Al}+\mathrm{Si})$. Long needles of intermetallic phases and the presence of the $\mathrm{Mg}_{2} \mathrm{Si}$ phase were also observed. There was no control of the thermal solidification parameters such as cooling rate and growth velocity, which makes the understanding of the microstructural characteristics less evident.

The AlSi10Mg alloys have demonstrated great potential and versatility in several processes involving melting and solidification. Therefore, the studies listed so far show the need to establish reliable interrelationships between microstructural and solidification thermal parameters and between microstructure aspects and properties, counting on cooling rate measurement and control. This type of approach can increase the prospect of microstructural and properties control for processes such as conventional casting, LW, PM and HPD. It is worth mentioning that in the case of rapid solidification processes such as AM-related techniques, direct cooling rate measurements are more difficult due to the nature of the process, i.e., extremely high cooling rates and reduced times [18].

Because of their high strength-to-weight ratio, heat-treatable capability, and excellent castability, Al-Si-Mg alloys are commonly used to manufacture components for the automotive and aerospace sectors of the industry. According to precedent findings, Copper $(\mathrm{Cu})$ and $\mathrm{Mg}$ are used in $\mathrm{Al}-\mathrm{Si}$ foundry alloys to produce typical precipitation hardening phases such as $\mathrm{Al}_{2} \mathrm{Cu}, \mathrm{Mg}_{2} \mathrm{Si}$, and $\mathrm{Al}_{2} \mathrm{CuMg}$, which can provide the alloy with improved mechanical properties [19,20]. Dunn and Dickert [21] demonstrated that adding Mg up to 0.55 percent might improve the tensile properties and hardness of the A380 and 383 alloys. Those alloys for which this Mg limit has been established have high $\mathrm{Si}$, but also high $\mathrm{Cu}$ and zinc $(\mathrm{Zn})$. In the case of the ternary $\mathrm{Al}-10 \mathrm{wt} . \% \mathrm{Si}(-\mathrm{Mg})$ alloys, the $\mathrm{Mg}$ limit has not been verified so far, to the best of the present authors' knowledge. High-silicon Al-SiMg alloys are specifically engineered for high integrity structural casting components. These alloys 
have a broad variety of property levels to satisfy the criteria for hardness, high mechanical properties, and crash efficiency. Moreover, Al-Si-Mg alloys, in addition to their excellent corrosion resistance, can be used to cast thin and massive structural parts due to their extremely high fluidity [22].

A transient directional solidification casting was used in this study to allow two (2) Al10wt.\% Si (-0.45 and $-1 \mathrm{wt} . \% \mathrm{Mg})$ alloys with substantially different microstructures and tensile properties to be generated. The differences in cooling rates, growth velocities, dendritic growth (either primary or secondary arms), phase constitution and tensile properties between both directionally solidified Al-Si-Mg alloys have been investigated. A number of techniques including CALPHAD, optical and scanning electronic microscopies, thermal analysis and mechanical tests were used to clarify how $\mathrm{Mg}$ content and cooling rate might affect output disparities in either dendritic growth or tensile properties.

\section{Experimental procedure}

In an induction furnace with a Si carbide crucible covered with zircon, two alloys were prepared using commercially pure $\mathrm{Al}(>99.9$ percent purity), Si ( $>99.7$ percent purity), and $\mathrm{Mg}(>$ 99.5 percent purity). To generate the desired ternary Al-10wt.\% Si (-0.45 and 1wt.\% Mg) alloys, appropriate quantities of $\mathrm{Mg}$ and $\mathrm{Si}$ were added to the melt. They were applied to the molten bath in small pieces so that they could melt easily. After, the molten alloys were poured into a split AISI 304 stainless steel mold with an internal diameter of $60 \mathrm{~mm}$, a height of $157 \mathrm{~mm}$, and a wall thickness of 5 $\mathrm{mm}$. To minimize radial heat losses, a coating of insulating alumina was applied to the vertical inner mold wall. A thin AISI 1020 carbon steel plate was used to seal the bottom of the mold ( $3 \mathrm{~mm}$ thick). The inner plate's surface was ground with \#1200 finishing sandpaper.

The molten alloy was degassed with argon gas for 2 minutes using a perforated quartz tube before being scorified with the appropriate flux and cast as $60 \mathrm{~mm}$ x $157 \mathrm{~mm}$ cylindrical ingots. A directional solidification method, as described in previous articles $[23,24]$, was used to achieve nonstationary heat flow conditions during the production of the castings. To allow continuous temperature measurements during solidification, 8 fine K-type thermocouples were mounted along the length of the casting. The thermocouple tips were set in distinct longitudinal points until $74 \mathrm{~mm}$, with 
the cooled bottom of the mold serving as a reference. As a result, temperature shifts may be used to track the directional growth of the alloy casting. With thermocouples in place and activated, the alloy was poured into the mold and the electric heaters were turned off; additionally, when the programmed melt overheating was reached, the regulated water flow was turned on.

After the Al-Si-Mg alloys castings were produced, longitudinal and transverse section samples were extracted from them by using a precision saw. Metallography was used to examine eight (8) sections at different distances from the cooled surface of the casting. Primary $\left(\lambda_{1}\right)$ and secondary $\left(\lambda_{2}\right)$ dendritic arm spacings were measured using an Olympus Metallurgical Microscope (model GX51) while the dendritic arrays were being clearly visualized. The intercept procedure was used on longitudinal samples to detect $\lambda_{2}$ whereas the triangle method distinguished $\lambda_{1}$. Both spacing values were defined by the average counting of 50 measurements per position along the casting length [25].

To supplement the optical microstructural characterization, a scanning electron microscope (SEM-EDS) FEI (Inspect S50L) was used. This instrument was used to examine transverse section samples of the DS Al-10wt.\% Si-0.45wt.\% Mg Al-10wt.\% Si-1wt.\% Mg alloys castings, and EDS elemental mapping was performed to assess the relative distribution of the formed phases in each alloy.

Tensile experiments were carried out on transverse specimens machined from various locations along the length of the DS castings. Three specimens per position of interest were prepared in accordance with the ASTM Standard E 8M specifications and tested at a strain rate of $3 \times 10^{-3} \mathrm{~s}^{-1}$.

\section{Results and discussion}

The thermal profiles registered for the two Al-Si-Mg alloys are shown in Fig. 1. Each line shows the time evolution of the temperature from the liquid metal at a certain point across the length of the casting. Smaller values of positions $(\mathrm{P})$ such as $5 \mathrm{~mm}$ and $10 \mathrm{~mm}$ might report smaller distances in relation to the cooled base of the casting. Whereas higher "P" values mean more distant positions, with softer cooling profiles. These profiles will be very useful in order to determine cooling rates and 
growth velocities as will be seen next. The liquidus temperatures $\left(\mathrm{T}_{\mathrm{L}}\right)$ are signed with horizontal dashed lines in the graphs. These temperatures were obtained due to examining the results observed in cooling curves registered at very slow cooling down.

The profiles of the associated positions in each alloy casting are very similar, which indicates to a certain extent little influence of the increase in $\mathrm{Mg}$ on the drop in temperature during directional solidification. By observing the Scheil solidification diagrams in Fig. 2, it can be seen that the freezing solidification intervals of the two alloys are very similar. This corroborates the little comparative variations in the thermal profiles of the same positions between both alloys around the liquidus temperature. Even though Timelli and Bonollo [26] affirmed that the Mg content has some impact on fluidity of $\mathrm{Al}-\mathrm{Si}$ alloys, decreasing it with increasing $\mathrm{Mg}$ content, it appears that contents that are as low as those applied to the alloys evaluated here may not be enough to significantly alter the alloy fluidity.

Solidification interval and melt fluidity are considered key factors in altering thermal conductance at the metal/mold interface $[27,28]$. These factors influence the thermal history during solidification. In the present case it seems not to be sufficient to cause significant changes, as can be seen in Fig. 1. 

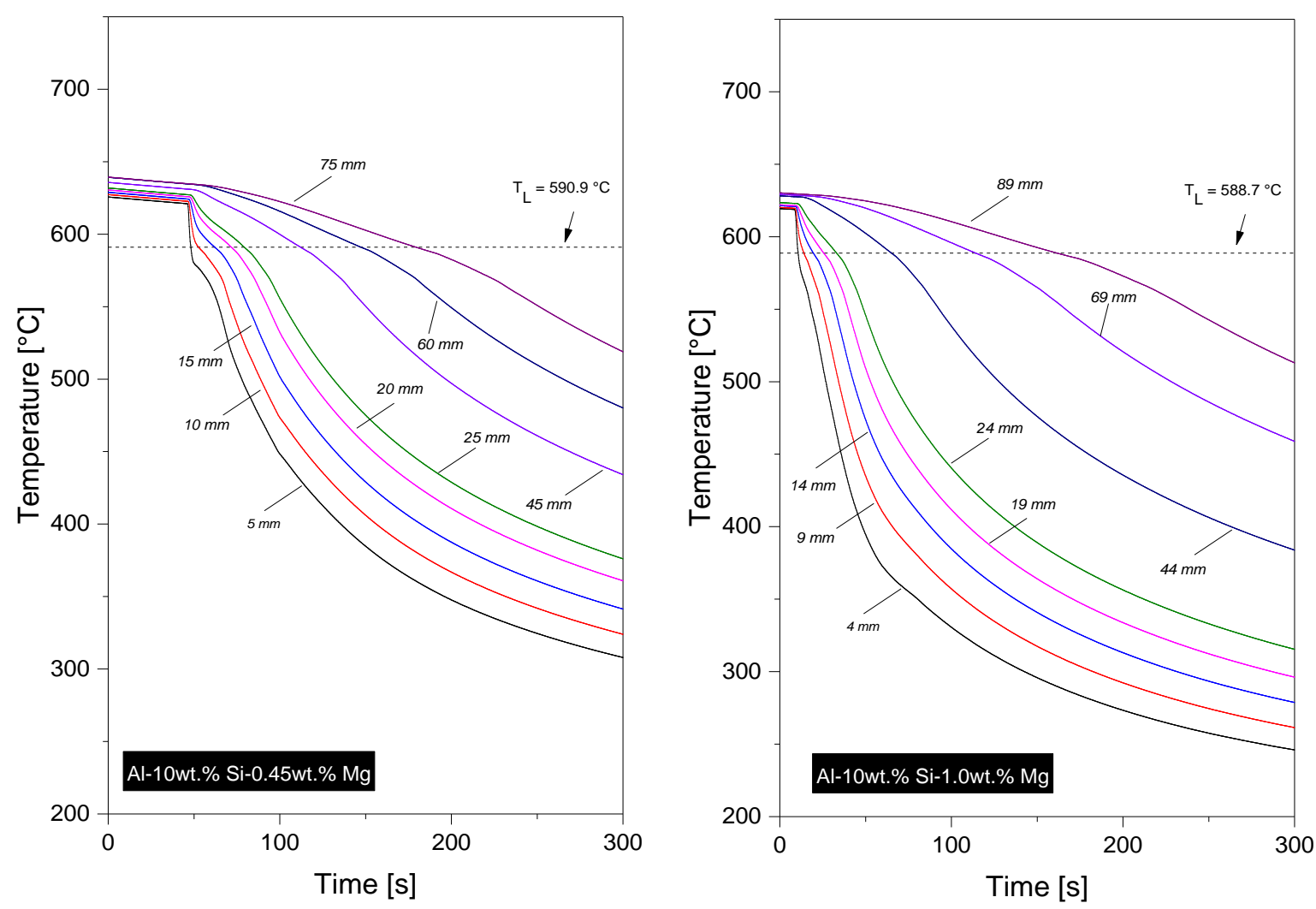

Fig. 1 - Temperature $\mathrm{x}$ time profiles registered at different points along the length of the casting during solidification of Al-10wt.\% Si-(Mg) alloys.

The series of phases forming, and their proportions are critical for controlling multicomponent alloys solidification. Given that the addition of Mg might change the precipitation series from easy to complicate in $\mathrm{Al}-\mathrm{Si}$ alloys, the CALPHAD approach becomes an important tool for modeling multicomponent alloys [29].

Fig. 2 depicts the Scheil evolutions of the fractions of the phases produced for each alloy as a function of temperature. It should be noted that the primary $\alpha$-Al phase may correspond to $22 \%$ of mass fraction, growing for higher temperatures. For lower temperatures, the Si phase precipitates until the temperature attains the eutectic plateau. The proportions of ternary eutectic are $6 \%$ and $17 \%$ for the Al-10wt.\% Si-0.45wt.\% Mg and Al-10wt.\% Si-1wt.\% Mg alloys, respectively. This means that the Scheil calculations predict a fraction of ternary eutectic 3 times higher for the alloy with more $\mathrm{Mg}$. 
Al-10wt.\% Si - 0.45wt.\% Mg

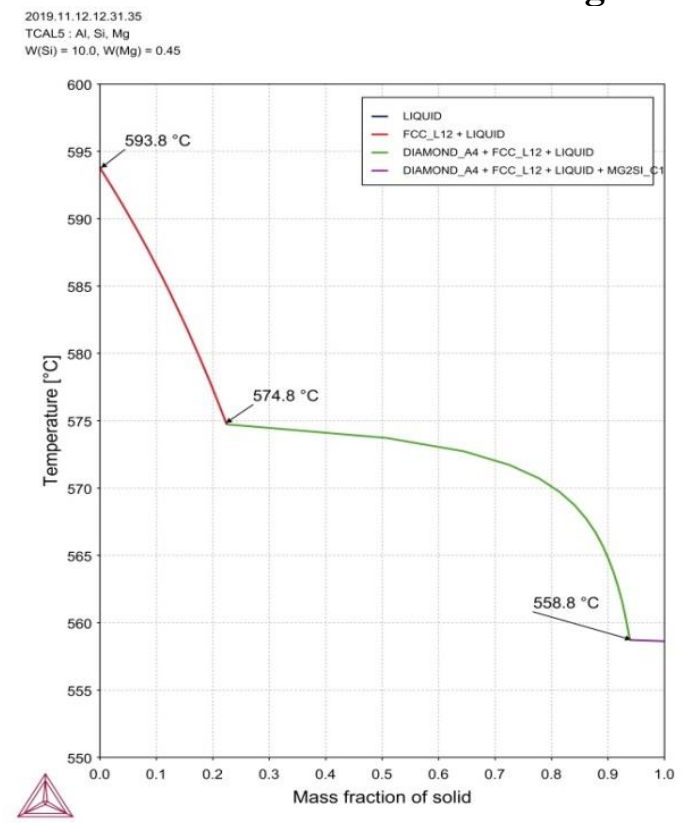

Al-10wt.\% Si -1wt.\% Mg

2020.11.30.18.19.0

TCAL7 : Al, Si, Mg
$W(\mathrm{Si})=10.0, \mathrm{~W}(\mathrm{Mg})=1.0$

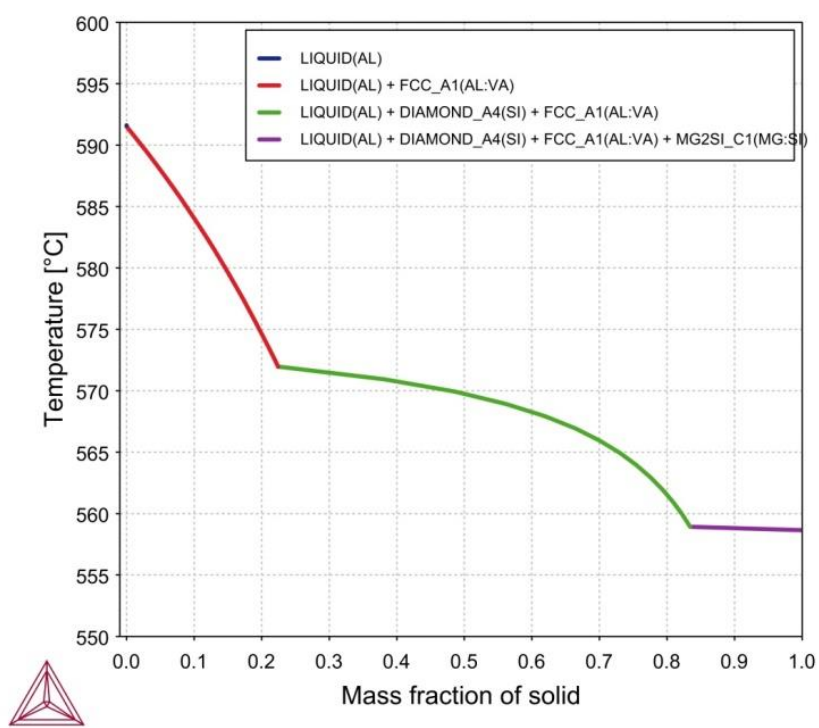

Fig. 2 - Scheil diagrams showing the solidification sequences related to the Al-10wt.\% Si-0.45wt.\% $\mathrm{Mg}$ and $\mathrm{Al}-10 \mathrm{wt} . \% \mathrm{Si}-1 \mathrm{wt} . \% \mathrm{Mg}$ alloys.

The data in Fig. 1 allow for the tracking of liquidus isotherm developments during the cooling process. As such, plots of the position $(\mathrm{P})$ in the castings versus time $(\mathrm{t})$ of passage of the isotherm corresponding to each alloy could be generated. The liquidus growth velocities $\left(\mathrm{V}_{\mathrm{L}}\right)$ were obtained by taking the time derivative of these $\mathrm{P} \times \mathrm{t}$ functions, and the time-derivative of each cooling curve (dT/dt) was computed right after the liquidus isotherms passed by each thermocouple, thus permitting the liquidus cooling rate, $\dot{\mathrm{T}}$, to be determined as a function of $\mathrm{P}$. Cooling rate and growth velocity color maps for both alloys are plotted as a way of exemplifying the changes in these solidification thermal parameters along the casting length, as observed in Fig. 3. The parameter graduation is shown by the color scales on the right side of each map. 

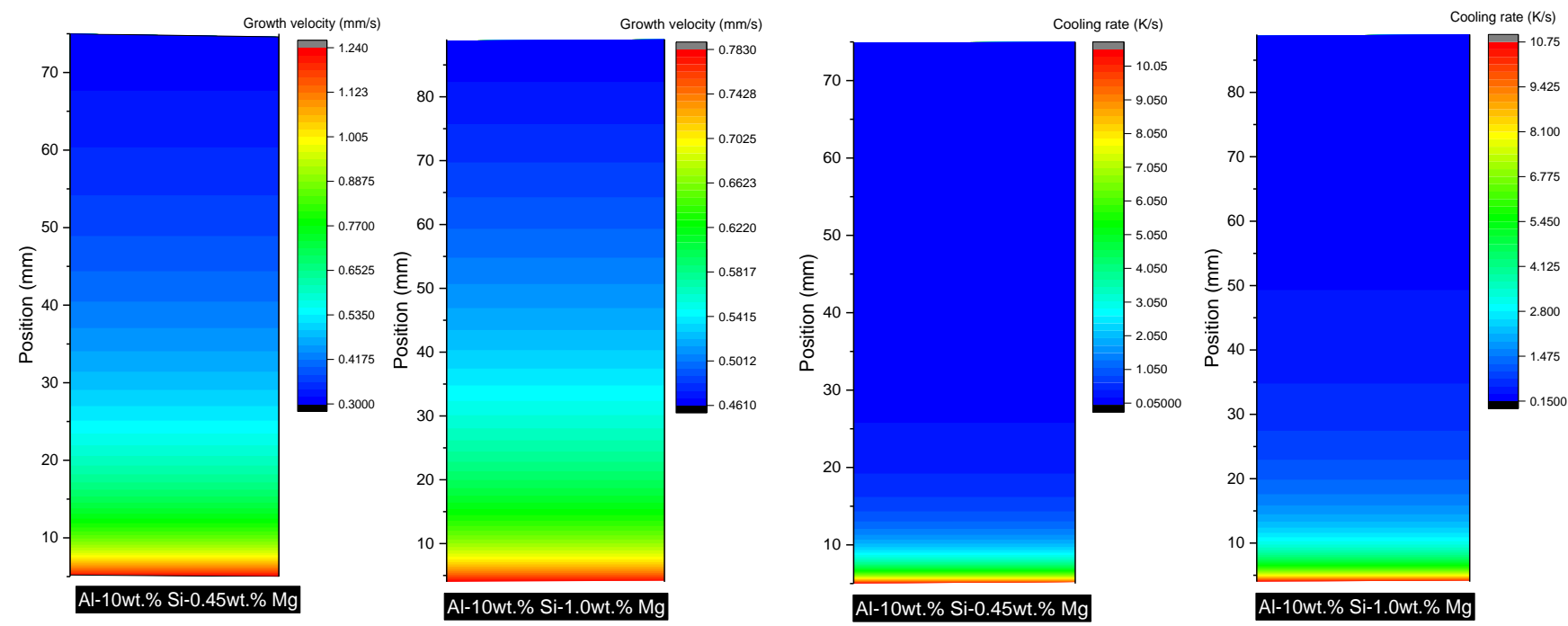

Fig. 3 - Representations in color maps of the evolution of growth velocities and cooling rates from top to bottom along the length of the solidified $\mathrm{Al}-\mathrm{Si}-\mathrm{Mg}$ bodies.

Most DS castings may have two main solidification zones that correspond to either columnar or equiaxed grains. These castings may present one of the two zones or both, depending mainly on the solidification conditions and alloy composition. Columnar grains often grow from the bottom mold surface, where thermal gradients are strong, and the growth is preferentially oriented in the direction of the heat flux. As soon as the gradients towards the top of the casting are reduced, equiaxed grains may nucleate in the remaining liquid [30,31]. In the case of the macrostructures in Fig. 4, starting high cooling rates provided a predominance of columnar macromorphology at approximately $85 \%$ of the length of the castings, regardless of alloy $\mathrm{Mg}$ content. 


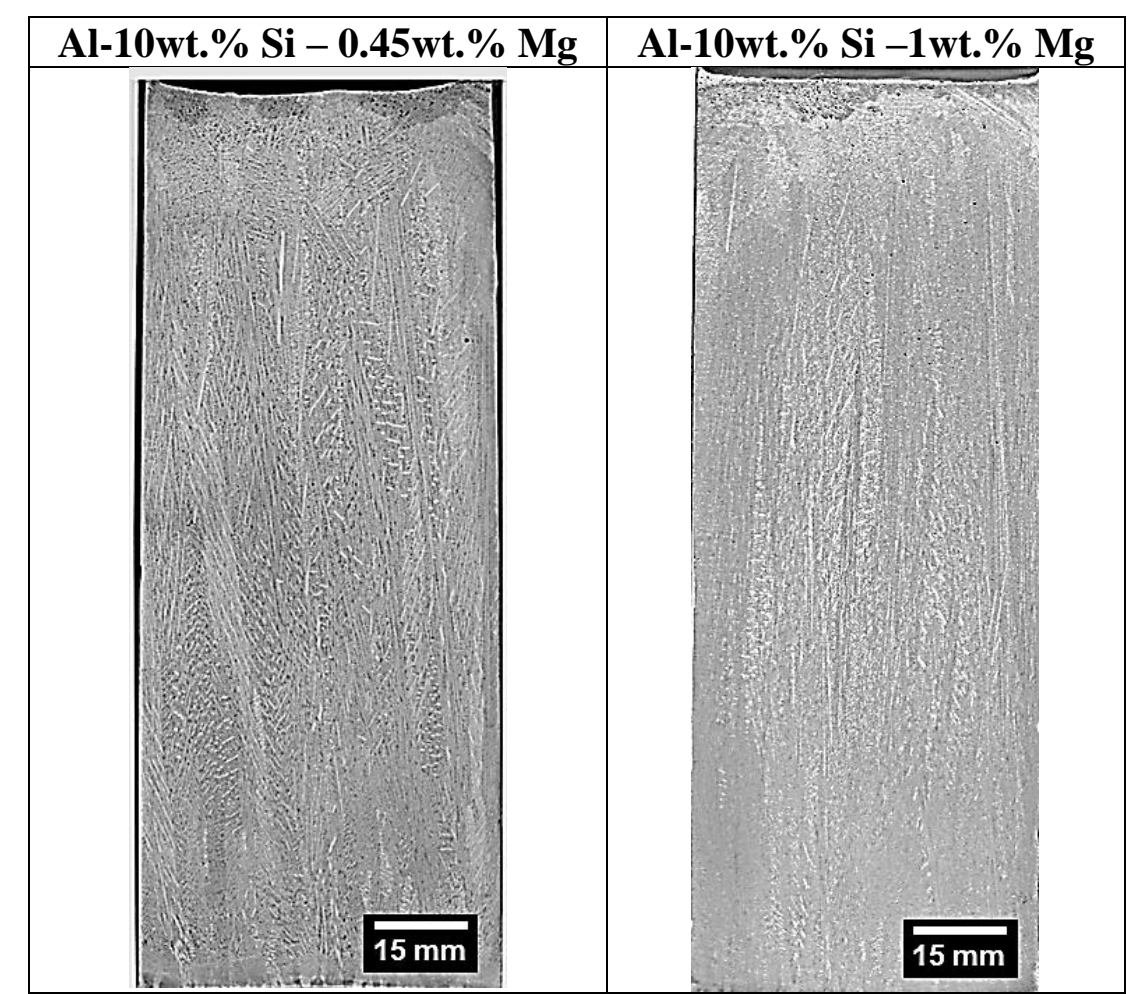

Fig. 4 - Columnar-type grain morphology revealed along the longitudinal section of the evaluated AlSi-Mg castings.

Light microstructures, as seen in Fig. 5 and Fig. 6, were revealed to verify the characteristics of the dendritic arrangements along the solidified castings. It is also possible to compare the lengthscale of the dendrites in both cross and longitudinal sections as a function of the thermal solidification parameters. These images were used to measure the primary (cross section) and secondary (longitudinal) dendritic spacings. For all levels of cooling rates, in addition to the $\alpha$-Al dendrites, the interdendritic regions (dark areas) are composed of $\mathrm{Si}$ and $\mathrm{Mg}_{2} \mathrm{Si}$, part of the eutectic constituent. It is also possible to perceive an effective microstructural thickening with the reduction in cooling rate and growth velocity. 


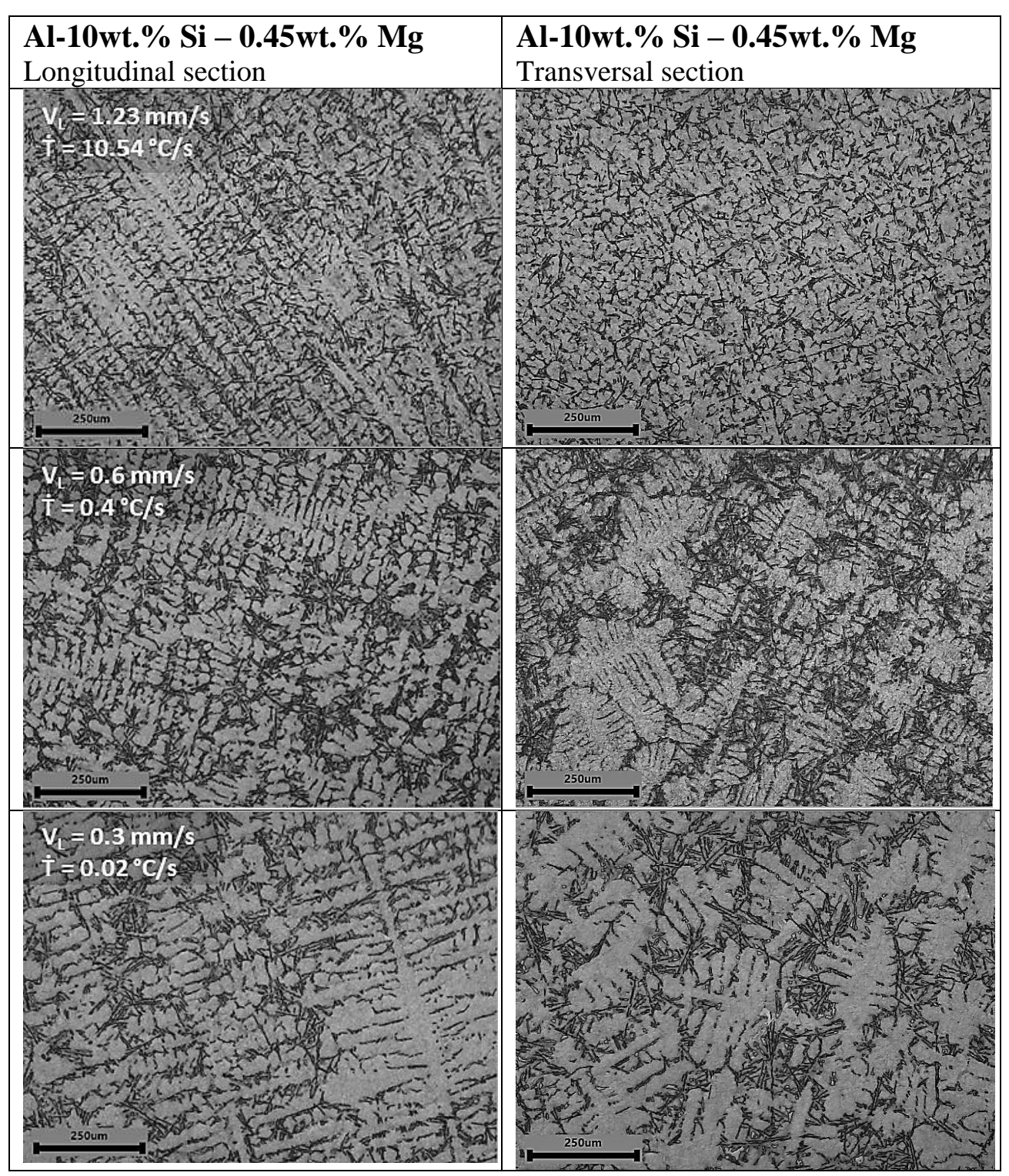

Fig. 5 - Light microstructures showing dendritic arrangements and their dependencies with cooling rates and growth velocities for the Al-10wt.\% Si-0.45wt.\% Mg alloy. 


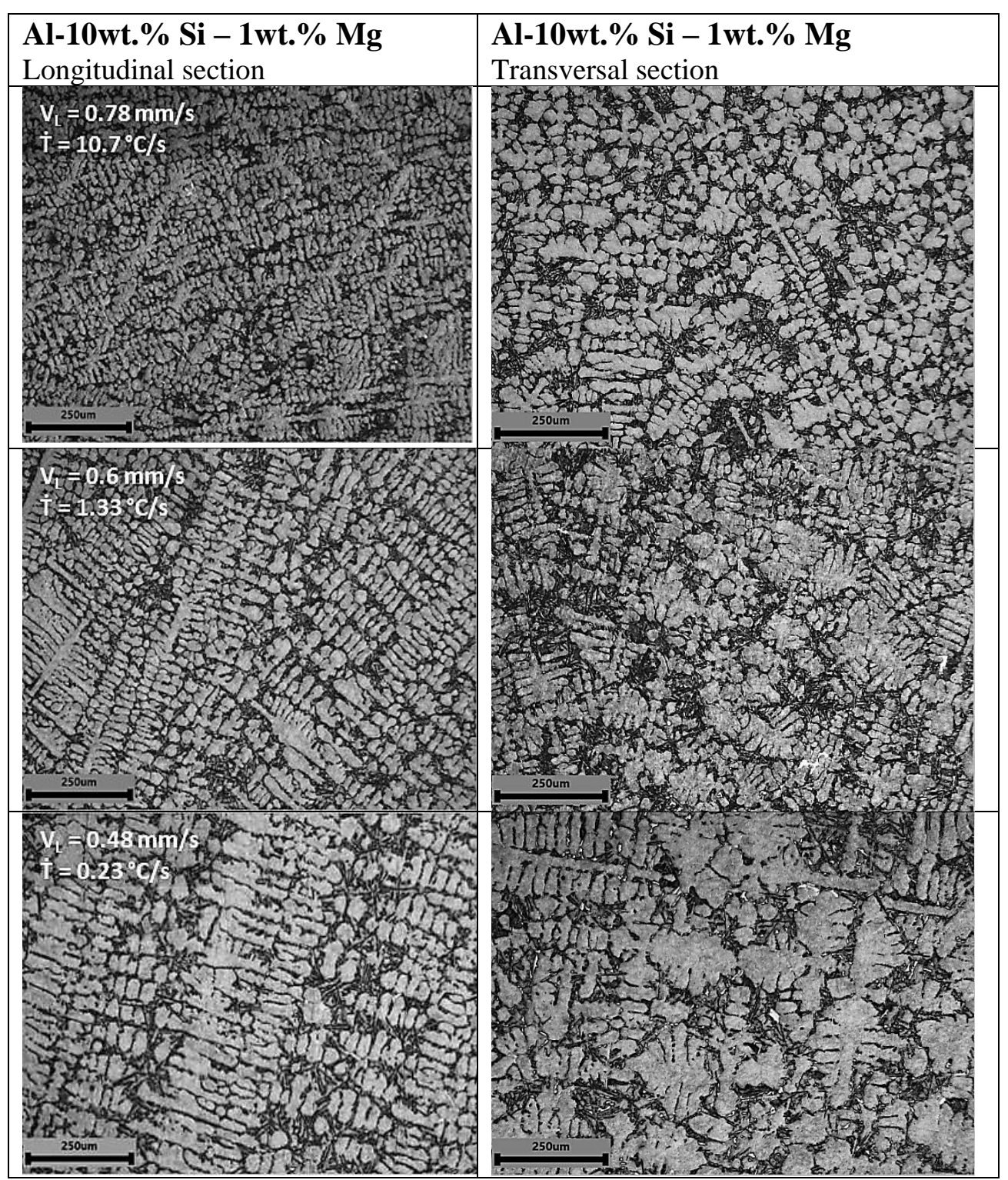

Fig. 6 - Light microstructures showing dendritic arrangements and their dependencies with cooling rates and growth velocities for the Al-10wt.\% Si-1wt.\% Mg alloy.

Fig. 7 depicts the secondary phase's morphologies at cooling rates around $10 \mathrm{~K} / \mathrm{s}$ for both examined alloys. The morphology of the $\mathrm{Mg}_{2} \mathrm{Si}$ phase (dark phase) in the ternary eutectic area is Chinese-script-like [32]. Si particles (light phase) show a lamellar morphology typically found in these alloys for a wide range of cooling rates $[33,34]$. SEM/EDS analyses with EDS elemental mappings in Fig. 7 show the element composition and distribution in each phase. According to Liu and Kang [32], the addition of Mg to Al-Mg-Si alloys has a significant impact on the development of 
solidification microstructures. Moreover, increased Mg content promotes an increase in the fraction of $\mathrm{Mg}_{2} \mathrm{Si}$ particles. This was also observed in the present results.

(a) Al - 10 wt. $\% \mathrm{Si}-1$ wt. \% Mg
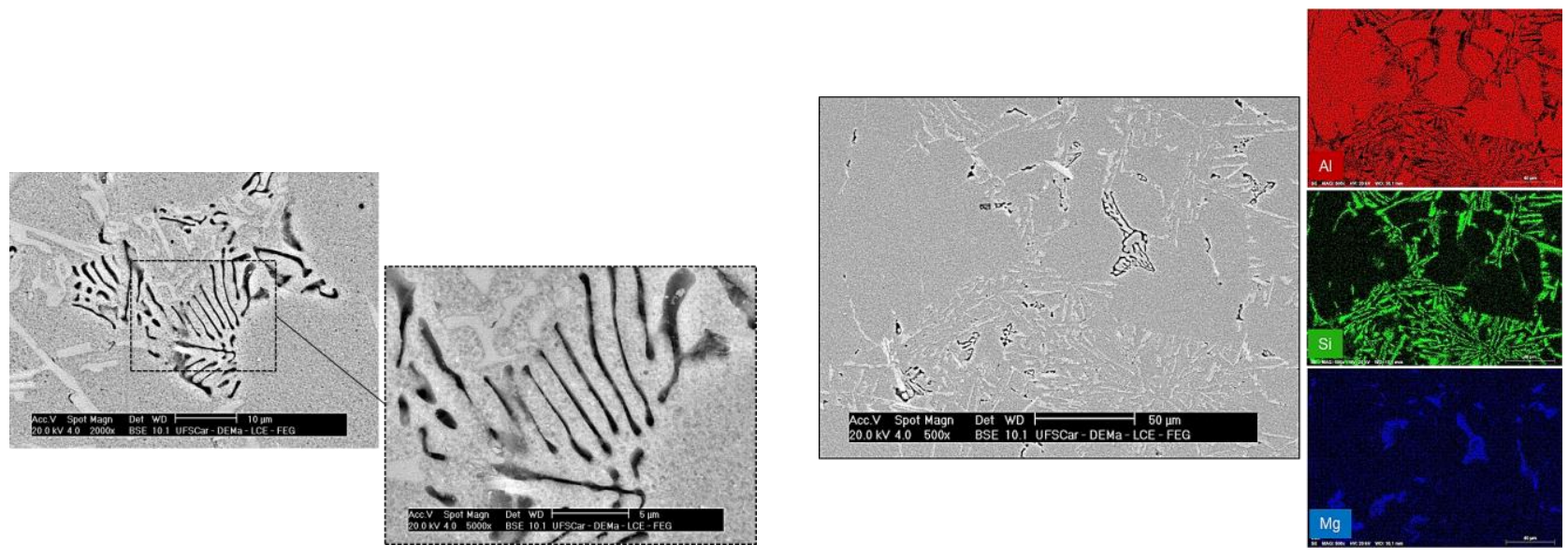

(b) Al - 10 wt. \% Si -0.45 wt. $\% \mathrm{Mg}$
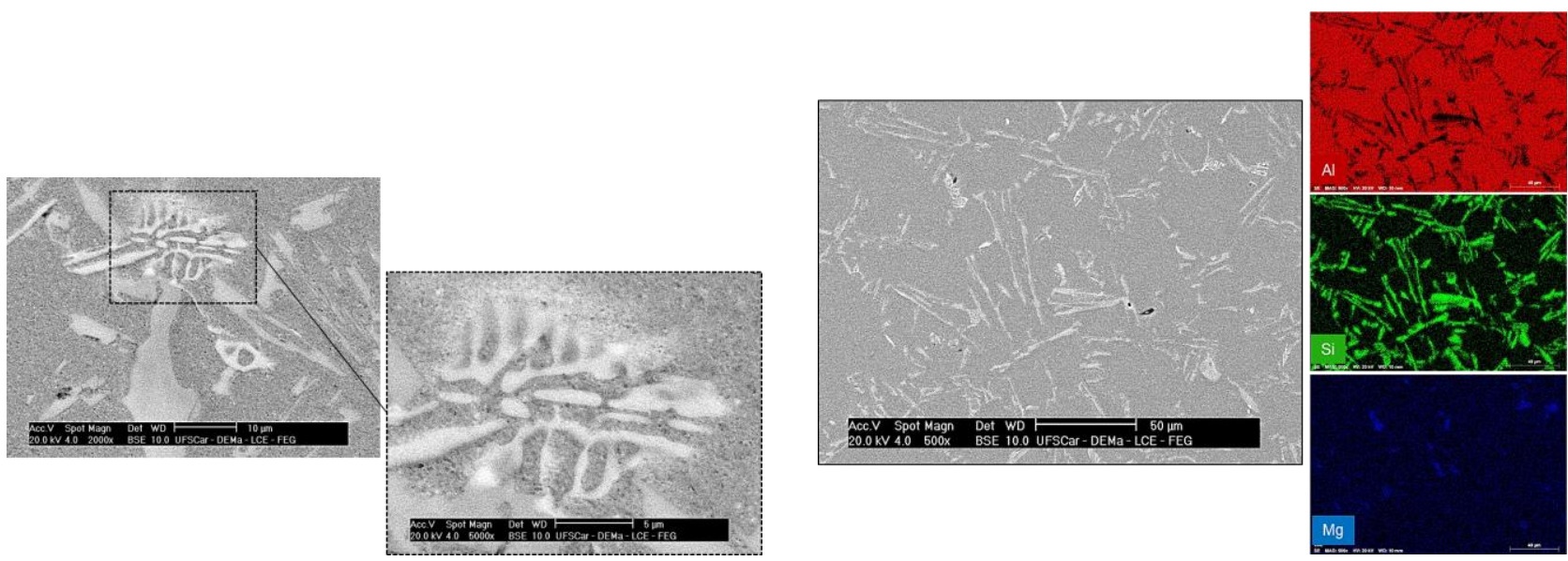

Fig. 7 - SEM images showing the formed phases, details with greater magnification and color mapping of the elements Al, Si and Mg: (a) Al-10 wt.\% Si-1 wt.\% Mg and (b) Al-10 wt.\% Si-0.45 wt. \% Mg.

The experimental evolutions of measured $\lambda_{1}$ and $\lambda_{2}$ are shown in Fig. 8. It shows expressive variations of values representative of the dendritic scale in the two alloys of interest. As expected, the length-scale related to $\lambda_{1}$ is much higher as compared with the $\lambda_{2}$ scale size. 

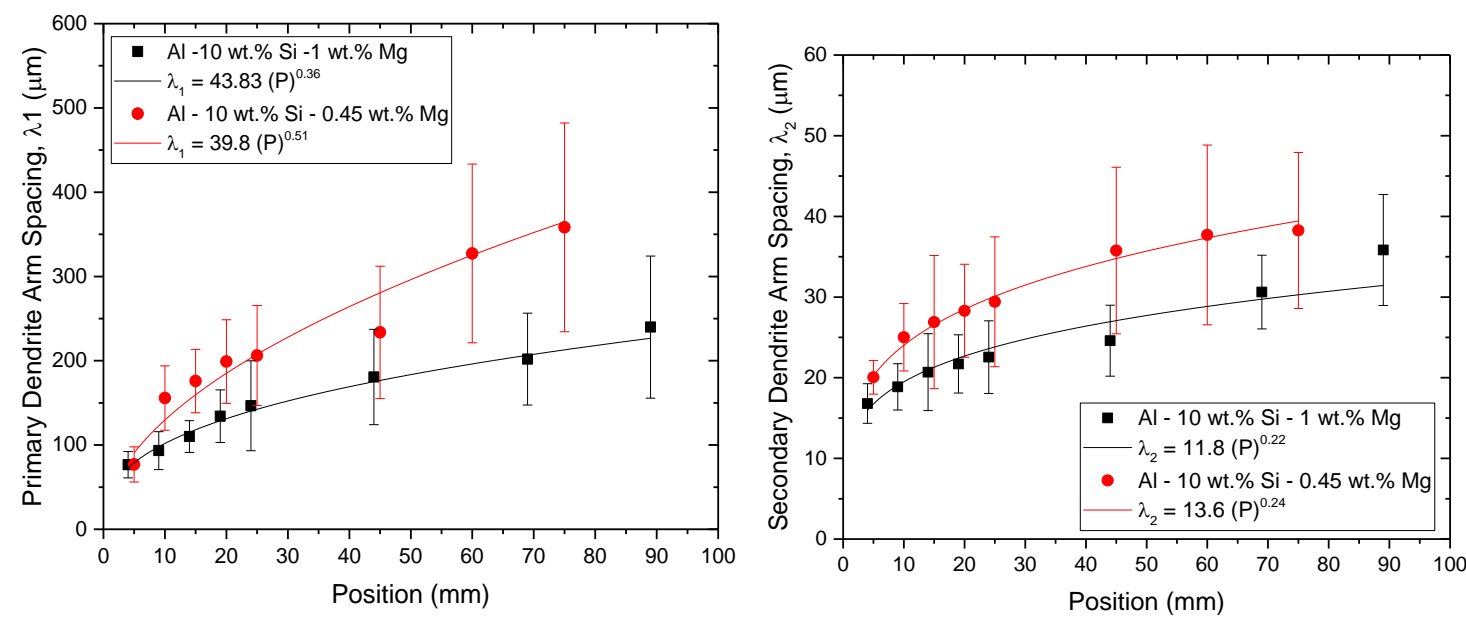

Fig. 8 - Experimental variations of $\lambda_{1}$ and $\lambda_{2}$ against position from the metal-mold interface along the length of the Al-10 wt.\% Si-1wt.\% Mg and Al-10 wt.\% Si-0.45 wt.\% Mg alloys castings.

Fig. 9 shows a comparison of further results for the Al-10 wt.\% Si-1wt.\% Mg and Al-10 wt.\% Si-0.45 wt.\% Mg alloys. In the matter of $\lambda_{1}$ growth versus $\dot{\mathrm{T}}, \mathrm{a}-0.4$ exponent was matched with a single relation being able to represent the whole set of experimental points of both alloys. While the exponent -0.55 is more commonly used in this type of scaling relation for binary $\mathrm{Al}$ alloys [35,36], the solidification of ternary alloys with more complex phases formation may have induced a slightly lower exponent. Another assessment involved plotting the $\lambda_{2}$ against the growth velocity, as also seen in Fig. 9. The alloy containing more $\mathrm{Mg}$ showed lower $\lambda_{2}$ values if a same growth velocity is considered.
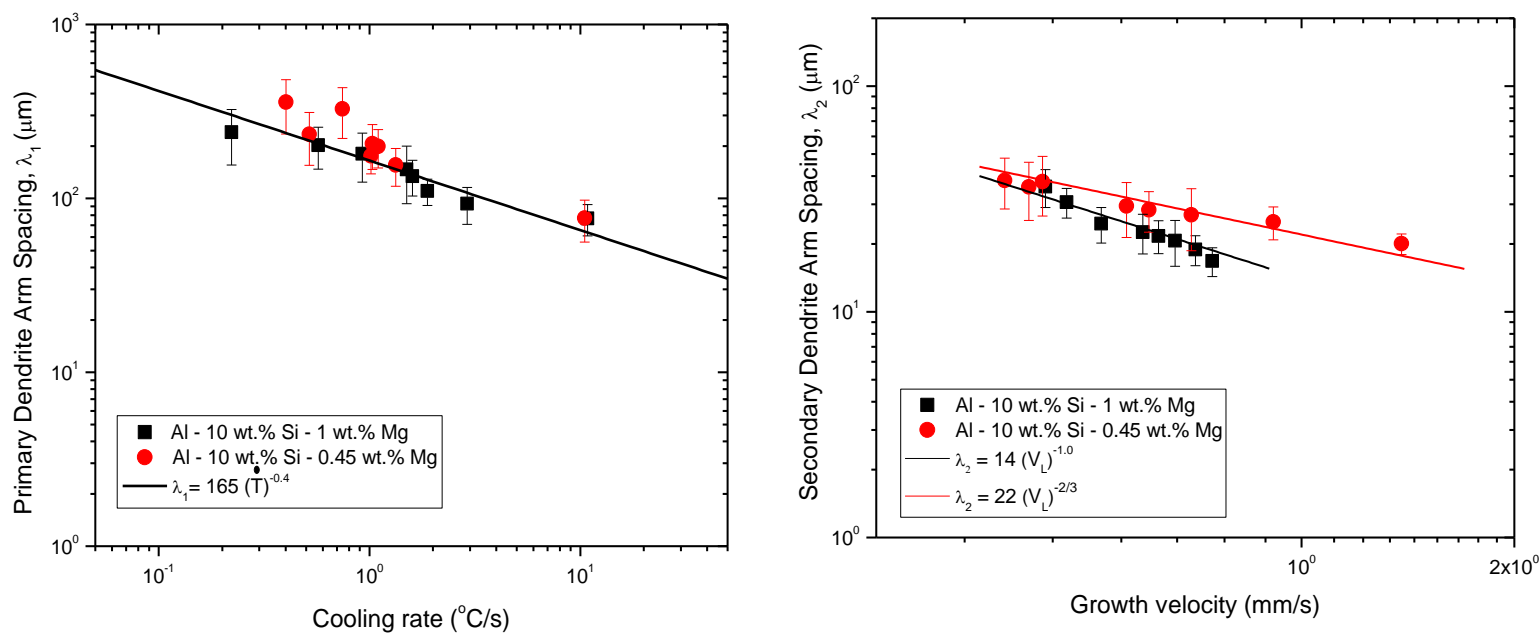

Fig. 9 - Scaling relations of microstructural spacings with thermal solidification parameters, such as cooling rate and growth velocity for the $\mathrm{Al}-\mathrm{Si}(-\mathrm{Mg})$ alloys. 
Fig. 10 shows how the ultimate tensile strength, yield tensile strength and elongation values of the DS Al-Si-Mg alloys castings differ over their microstructural range. The plots were proposed on a Hall-Petch basis. As previously shown in Fig. 9, the quantified dendrite interphase spacing of the Alrich matrix, $\lambda_{1}$, is that related to the different cooling rates measured for the solidified samples. While the properties of the Al-10 wt.\% Si-0.45wt.\% Mg alloy are superior for coarser $\lambda_{1}$ spacing, the properties of $\mathrm{Al}-10 \mathrm{wt} . \% \mathrm{Si}-1 \mathrm{wt} . \% \mathrm{Mg}$ alloy are superior and stand out in relation to the entire data set for more refined microstructure arrangements. In terms of $\lambda_{1}$ such reversal behavior means values less than $150 \mu \mathrm{m}$ and $\lambda_{2}$ values less than $20 \mu \mathrm{m}$. The best balance of properties provided a yield tensile strength, $\sigma_{\mathrm{y}}$, of $142 \mathrm{MPa}$, an ultimate tensile strength, $\sigma_{\mathrm{u}}$, of $220 \mathrm{MPa}$ and an elongation, $\delta$, of $5 \%$.

This superior set of properties represents DS samples of the unmodified Al-10 wt.\% Si-1wt.\% $\mathrm{Mg}$ alloy with $\lambda_{2}$ of about $16 \mu \mathrm{m}$. These values are higher than those reported by Zhang et al. [1] in samples of the Sr-modified Al-10Si-0.6Mg-0.6Mn alloy solidified via PM casting with $\lambda_{2}$ of $12 \mu \mathrm{m}$. The tensile properties under such conditions were $\sigma_{u}$ of $180 \mathrm{MPa}, \sigma_{\mathrm{y}}$ of $120 \mathrm{MPa}$ and $\delta$ of $1.8 \%$. For the present DS samples, a $22 \%$ increase in $\sigma_{\mathrm{u}}, 18 \%$ increase in $\sigma_{\mathrm{y}}$ and a $177 \%$ increase in $\delta$ over that properties on the PM casting condition attained by Zhang et al. [1]. This is an interesting comparison because the results under PM casting involve an alloy with eutectic Si modification and insertion of $\mathrm{Mn}$ in addition to greater dendritic fineness. This shows that a slight increase in $\mathrm{Mg}$ up to $1 \mathrm{wt} . \%$ can result in significant improvements. Moreover, these properties tend to improve even more with T6 treatment, as shown in other studies in the literature $[1,16,17]$.

Li et al. [37] demonstrated that the ideal Mg content for the as-cast Al-10Si-series alloys remains around $2 \mathrm{wt} . \% \mathrm{Mg}$, even observing good balance of tensile properties in the alloy containing $0.8 \mathrm{wt} . \% \mathrm{Mg}$, that are $\sigma_{\mathrm{y}}$ of $96 \mathrm{MPa}, \sigma_{\mathrm{u}}$ of $212 \mathrm{MPa}$ and $\delta$ of $12 \%$. In this study, additions of 0.4 wt., 0.8 wt., 1.2 wt., 2 wt. and 3 wt. $\% \mathrm{Mg}$ to the $\mathrm{Al}-10 \mathrm{wt}$. $\%$ Si alloy solidified in a permanent steel mold were investigated. However, variations in cooling rates and dendritic spacing were not analyzed. The observations of this study are especially useful to explain the simultaneous increase in ductility and strength for the refined samples of the Al-10 wt.\% Si-1wt.\% Mg alloy as compared with the Al-10 
wt.\% Si-0.45wt.\% Mg alloy. At the 1.0wt.\% Mg addition level, crack initiation and dissemination were minimized as compared to the $\mathrm{Al}-10 \mathrm{wt} . \% \mathrm{Si}-0.45 \mathrm{wt} . \% \mathrm{Mg}$ alloy because the high $\mathrm{Mg}$ addition level caused even more tortuous dendrite borders, which is directly conducive to increased strength and ductility. Moreover, because of the substantial reduction in growing space induced by the refinement of $\lambda_{2}$, the increased $\mathrm{Mg}$ content indirectly facilitated the size reduction of the $\mathrm{Mg}_{2} \mathrm{Si}$ intermetallic particles, improving both strength and ductility.
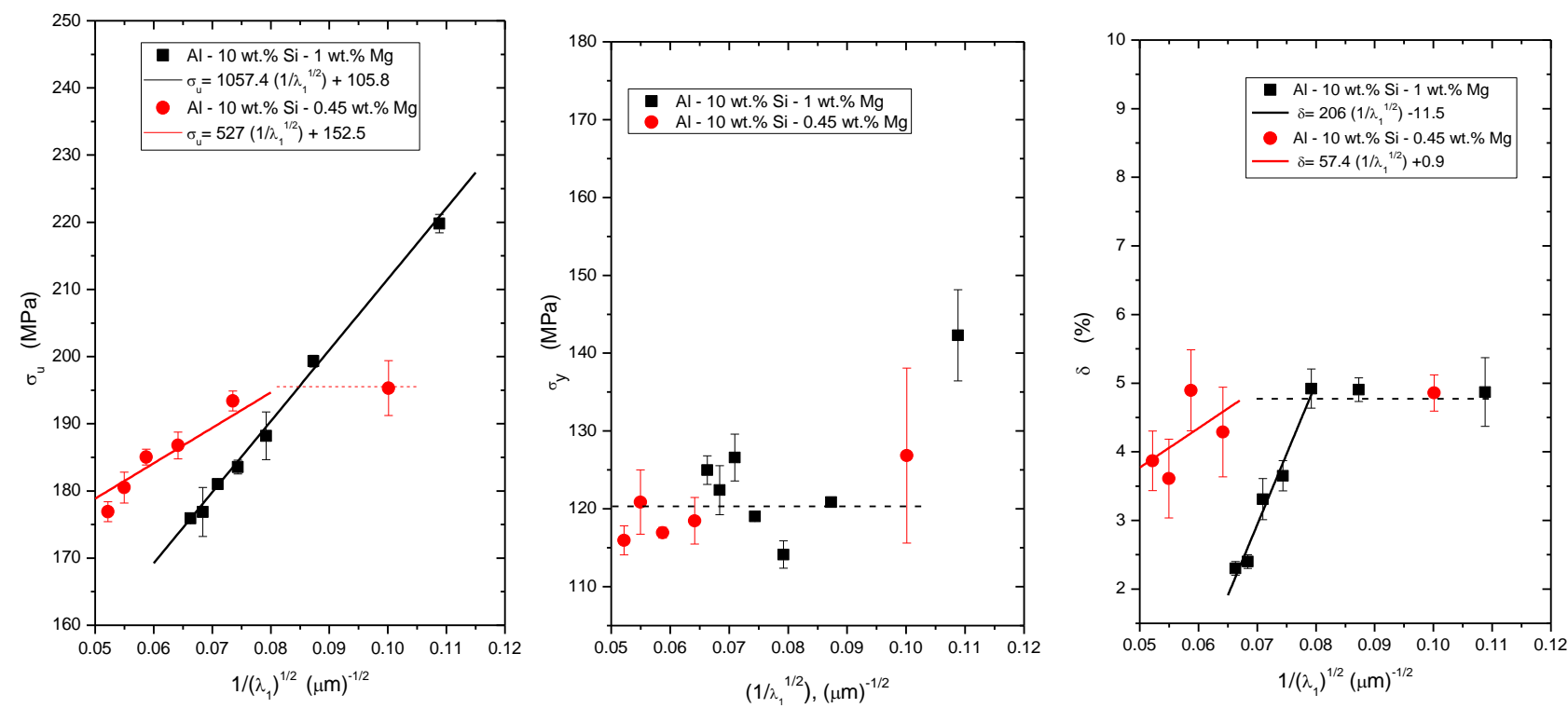

Fig. 10 - Tensile properties of the Al-10 wt.\% Si-1wt.\% Mg and Al-10 wt.\% Si-0.45 wt.\% Mg alloys as function of $\lambda_{1}$.

\section{Conclusions}

- The macrostructure of both DS Al-10wt.\% Si-0.45wt.\% Mg and Al-10wt.\% Si-1wt.\% Mg alloys castings is characterized by a columnar macromorphology at approximately $85 \%$ of the length of the castings from the cooled bottom. The microstructure of both alloys is formed by an $\alpha$-Al matrix having a dendritic arrangement with well-defined primary $\left(\lambda_{1}\right)$ and secondary $\left(\lambda_{2}\right)$ arms, with interdendritic regions composed of the eutectic mixture: $\alpha$-Al; Si particles of lamellar morphology and Chinese-script-like $\mathrm{Mg}_{2} \mathrm{Si}$ intermetallics. 
- Dendritic growth laws were experimentally determined relating $\lambda_{2}$ to the growth velocity $\left(\mathrm{v}_{\mathrm{L}}\right)$, and $\lambda_{1}$ to the solidification cooling rate $(\dot{\mathrm{T}})$, that is:

Al-10wt. $\%$ Si-0.45wt.\% Mg: $\lambda_{2}=22\left(\mathrm{v}_{\mathrm{L}}\right)^{-2 / 3}$

Al-10wt. $\%$ Si-1wt. $\% \mathrm{Mg}: \lambda_{2}=14\left(\mathrm{v}_{\mathrm{L}}\right)^{-1.0}$

and $\lambda_{1}=165(\dot{\mathrm{T}})^{-0.4}$ for both alloys, where $\lambda[\mu \mathrm{m}] ; \dot{\mathrm{T}}\left[{ }^{\circ} \mathrm{C} / \mathrm{s}\right]$ and $\mathrm{v}_{\mathrm{L}}[\mathrm{mm} / \mathrm{s}]$.

- According to Hall-Petch type relationships, the ultimate tensile strength $\left(\sigma_{u}\right)$ and elongation ( $\delta$ ) of both alloys studied varied with $\lambda_{1}$ :

Al-10wt. $\%$ Si-0.45wt. $\% \mathrm{Mg}: \sigma_{\mathrm{u}}=527\left(1 / \lambda_{1}\right)^{1 / 2}+152.5$ and $\delta=57.4\left(1 / \lambda_{1}\right)^{1 / 2}+0.9$

Al-10wt.\% Si-1wt.\% Mg: $\sigma_{u}=1057.4\left(1 / \lambda_{1}\right)^{1 / 2}+105.8$ and $\delta=206\left(1 / \lambda_{1}\right)^{1 / 2}-11.5$

where $\sigma_{\mathrm{u}}[\mathrm{MPa}]$ and $\delta[\%]$. The tensile properties of the Al-10 wt.\% Si-1wt.\% Mg alloy were shown to be superior and stand out in relation to the entire data set for more refined microstructure arrangements $\left(\lambda_{1}<150 \mu \mathrm{m}\right.$ and $\left.\lambda_{2}<20 \mu \mathrm{m}\right)$. The best balance of properties provided a yield tensile strength, $\sigma_{\mathrm{y}}$, of $142 \mathrm{MPa}$, ultimate tensile strength, $\sigma_{\mathrm{u}}$, of $220 \mathrm{MPa}$ and elongation, $\delta$, of $5 \%$.

\section{Funding}

This work was supported by FAPESP- São Paulo Research Foundation, Brazil (grant 2019/23673-7); Capes- Coordenação de Aperfeiçoamento de Pessoal de Nível Superior, Brazil (Funding Code 001); and CNPq- National Council for Scientific and Technological Development, Brazil.

\section{Conflicts of interest}

We announce that we have no financial or personal arrangements with other individuals or organizations that may improperly affect our work, and that we have no technical or other personal interest in any good, service, or business that could be construed as affecting the results presented in, or the analysis of, the manuscript entitled. 


\section{Ethical approval}

This article does not contain any studies with human participants or animals performed by any of the authors.

\section{Informed consent}

The enclosed manuscript has been accepted by all of the informed authors.

\section{Data availability}

The data that support the findings of this study are available from the corresponding author, JES, upon reasonable request.

\section{References}

[1] Z. Zhang, M.-Y. Liu, F. Breton, X.-G. Chen, Microstructure and Mechanical Properties of AlSi10Mg Permanent Mould and High Pressure Vacuum Die Castings, in: Proc. 16th Int. Alum. Alloy. Conf., Canadian Institute of Mining, Metallurgy \& Petroleum, 2018.

[2] C.M. Gourlay, H.I. Laukli, A.K. Dahle, Defect band characteristics in Mg-Al and Al-Si highpressure die castings, Metall. Mater. Trans. A. 38 (2007) 1833-1844. https://doi.org/10.1007/s11661007-9243-1.

[3] S. Ji, Y. Wang, D. Watson, Z. Fan, Microstructural evolution and solidification behavior of Al-Mg-Si alloy in high-pressure die casting, Metall. Mater. Trans. A Phys. Metall. Mater. Sci. 44 (2013) 3185-3197. https://doi.org/10.1007/s11661-013-1663-5.

[4] Q. Yan, B. Song, Y. Shi, Comparative study of performance comparison of AlSi10Mg alloy prepared by selective laser melting and casting, J. Mater. Sci. Technol. 41 (2020) 199-208. https://doi.org/10.1016/j.jmst.2019.08.049.

[5] R. Kakitani, R.V. Reyes, A. Garcia, N. Cheung, J.E. Spinelli, Effects of Melt Superheating on the Microstructure and Tensile Properties of a Ternary Al-15 Wt Pct Si-1.5 Wt Pct Mg Alloy, Metall. Mater. Trans. A Phys. Metall. Mater. Sci. 50 (2019). https://doi.org/10.1007/s11661-018-5058-5.

[6] A. Niklas, A. Bakedano, S. Orden, M. da Silva, E. Nogués, A.I. Fernández-Calvo, Effect of Microstructure and Casting Defects on the Mechanical Properties of Secondary AlSi10MnMg(Fe) Test Parts Manufactured by Vacuum Assisted high Pressure Die Casting Technology, Mater. Today Proc. 2 (2015) 4931-4938. https://doi.org/10.1016/j.matpr.2015.10.059.

[7] S. Seifeddine, S. Johansson, I.L. Svensson, The influence of cooling rate and manganese content on the $\beta$-Al5FeSi phase formation and mechanical properties of Al-Si-based alloys, Mater. Sci. Eng. A. 490 (2008) 385-390. https://doi.org/10.1016/j.msea.2008.01.056. 
[8] P.R. Goulart, W.R. Osório, J.E. Spinelli, A. Garcia, Dendritic microstructure affecting mechanical properties and corrosion resistance of an Al-9 wt\% Si alloy, Mater. Manuf. Process. 22 (2007) 328-332. https://doi.org/10.1080/10426910701190345.

[9] P.R. Goulart, J.E. Spinelli, W.R. Osório, A. Garcia, Mechanical properties as a function of microstructure and solidification thermal variables of Al-Si castings, Mater. Sci. Eng. A. 421 (2006) 245-253. https://doi.org/10.1016/j.msea.2006.01.050.

[10] Y. Birol, Impact of grain size on mechanical properties of AlSi7Mg0.3 alloy, Mater. Sci. Eng. A. 559 (2013) 394-400. https://doi.org/10.1016/j.msea.2012.08.115.

[11] E. Samuel, B. Golbahar, A.M. Samuel, H.W. Doty, S. Valtierra, F.H. Samuel, Effect of grain refiner on the tensile and impact properties of Al-Si-Mg cast alloys, Mater. Des. 56 (2014) 468-479. https://doi.org/10.1016/j.matdes.2013.11.058.

[12] E.L. Rooy, Aluminum and Aluminum Alloys, in: Met. Handbook, Vol. 15, Cast., 9th ed., ASM International, 1988: pp. 743-770.

[13] E. Ghassemali, M. Riestra, T. Bogdanoff, B.S. Kumar, S. Seifeddine, Hall-Petch equation in a hypoeutectic Al-Si cast alloy: Grain size vs. secondary dendrite arm spacing, Procedia Eng. 207 (2017) 19-24. https://doi.org/10.1016/j.proeng.2017.10.731.

[14] S. Marola, D. Manfredi, G. Fiore, M.G. Poletti, M. Lombardi, P. Fino, L. Battezzati, A comparison of Selective Laser Melting with bulk rapid solidification of AlSi10Mg alloy, J. Alloys Compd. 742 (2018) 271-279. https://doi.org/10.1016/j.jallcom.2018.01.309.

[15] J.C. Pereira, E. Gil, L. Solaberrieta, M. San Sebastián, Y. Bilbao, P.P. Rodríguez, Comparison of AlSi7Mg0.6 alloy obtained by selective laser melting and investment casting processes: Microstructure and mechanical properties in as-built/as-cast and heat-treated conditions, Mater. Sci. Eng. A. 778 (2020). https://doi.org/10.1016/j.msea.2020.139124.

[16] A. Arici, Development Of Al-Si-Mg Alloys For Permanent Mold Casting And High-Pressure Vacuum Die Casting Applications, University Of Quebec At Chicoutimi, 2019.

[17] A. Arici, Z. Zhang, F. Breton, X.-G. Chen, Effect of Zr and V Additions on Microstructure and Mechanical Properties of the AlSi10Mg Cast Alloy, in: 16th Int. Alum. Alloy. Conf. - ICAA16, 2018.

[18] Y.J. Liu, Z. Liu, Y. Jiang, G.W. Wang, Y. Yang, L.C. Zhang, Gradient in microstructure and mechanical property of selective laser melted AlSi10Mg, J. Alloys Compd. 735 (2018) 1414-1421. https://doi.org/10.1016/j.jallcom.2017.11.020. 
[19] M.A. Moustafa, F.H. Samuel, H.W. Doty, S. Valtierra, Effect of $\mathrm{Mg}$ and Cu additions on the microstructural characteristics and tensile properties of Sr-modified Al-Si eutectic alloys, Int. J. Cast Met. Res. 14 (2002) 235-253. https://doi.org/10.1080/13640461.2002.11819442.

[20] P. Ouellet, F.H. Samuel, Effect of $\mathrm{Mg}$ on the ageing behaviour of Al-Si-Cu 319 type aluminium casting alloys, J. Mater. Sci. 34 (1999) 4671-4697. https://doi.org/10.1023/A:1004645928886.

[21] R. Dunn, W. Dickert, Magnesium effect on the strength of A380.0 and 383.0 aluminum die casting alloys, Die Cast. Eng. 19 (1975) 12-20.

[22] M. Baral, J. Ha, Y.P. Korkolis, Plasticity and ductile fracture modeling of an $\mathrm{Al}-\mathrm{Si}-\mathrm{Mg}$ diecast alloy, Int. J. Fract. 216 (2019) 101-121. https://doi.org/10.1007/s10704-019-00345-1.

[23] L.F. Gomes, B.L. Silva, A. Garcia, J.E. Spinelli, Dendritic Growth, Solidification Thermal Parameters, and Mg Content Affecting the Tensile Properties of Al-Mg-1.5 Wt Pct Fe Alloys, Metall. Mater. Trans. A. 48 (2017) 1841-1855. https://doi.org/10.1007/s11661-017-3978-0.

[24] R. V. Reyes, R. Kakitani, T.A. Costa, J.E. Spinelli, N. Cheung, A. Garcia, Cooling thermal parameters, microstructural spacing and mechanical properties in a directionally solidified hypereutectic Al-Si alloy, Philos. Mag. Lett. $96 \quad$ (2016) 228-237. https://doi.org/10.1080/09500839.2016.1192297.

[25] M. Gündüz, E. Çadırlı, Directional solidification of aluminium-copper alloys, Mater. Sci. Eng. A. 327 (2002) 167-185. https://doi.org/10.1016/S0921-5093(01)01649-5.

[26] G. Timelli, F. Bonollo, Fluidity of aluminium die castings alloy, Int. J. Cast Met. Res. 20 (2007) 304-311. https://doi.org/10.1179/136404608X286110.

[27] N. Cheung, N.S. Santos, J.M.V. Quaresma, G.S. Dulikravich, A. Garcia, Interfacial heat transfer coefficients and solidification of an aluminum alloy in a rotary continuous caster, Int. J. Heat Mass Transf. 52 (2009) 451-459. https://doi.org/10.1016/j.ijheatmasstransfer.2008.07.003.

[28] W.L.R. Santos, B.L. Silva, F. Bertelli, J.E. Spinelli, N. Cheung, A. Garcia, An alternative thermal approach to evaluate the wettability of solder alloys, Appl. Therm. Eng. 107 (2016) 431-440. https://doi.org/10.1016/j.applthermaleng.2016.06.177.

[29] A. Kroupa, Modelling of phase diagrams and thermodynamic properties using Calphad method - Development of thermodynamic databases, Comput. Mater. Sci. 66 (2013) 3-13. https://doi.org/10.1016/j.commatsci.2012.02.003.

[30] C.-A. Gandin, From constrained to unconstrained growth during directional solidification, Acta Mater. 48 (2000) 2483-2501. https://doi.org/10.1016/S1359-6454(00)00070-7. 
[31] C.A. Siqueira, N. Cheung, A. Garcia, Solidification thermal parameters affecting the columnar-to-equiaxed transition, Metall. Mater. Trans. A. 33 (2002) 2107-2118. https://doi.org/10.1007/s11661-002-0042-4.

[32] L. Liu, Y, B. Kang, S, The solidification process of Al-Mg-Si alloys, J. Mater. Sci. 32 (1997) 1443-1447. https://doi.org/10.1023/A:1018545732009.

[33] T. Hosch, L.G. England, R.E. Napolitano, Analysis of the high growth-rate transition in Al-Si eutectic solidification, J. Mater. Sci. 44 (2009) 4892-4899. https://doi.org/10.1007/s10853-009-37476.

[34] M. Warmuzek, Aluminum-Silicon Casting Alloys: Atlas of Microfractographs, ASM International, Materials Park, Ohio, 2016.

[35] M.D. Peres, C.A. Siqueira, A. Garcia, Macrostructural and microstructural development in Al-Si alloys directionally solidified under unsteady-state conditions, J. Alloys Compd. 381 (2004) 168-181. https://doi.org/10.1016/j.jallcom.2004.03.107.

[36] D.M. Rosa, J.E. Spinelli, A. Garcia, Tertiary dendrite arm spacing during downward transient solidification of Al-Cu and Al-Si alloys, Mater. Lett. 60 (2006) 1871-1874. https://doi.org/10.1016/j.matlet.2005.12.040.

[37] Q Li, F Qiu, B Dong, H Yang, S Shu, M Zha, Q Jiang, Investigation of the influences of ternary $\mathrm{Mg}$ addition on the solidification microstructure and mechanical properties of as-cast Al-10Si alloys, Mater Sci Eng A 798 (2020) 140247. https://doi.org/10.1016/j.msea.2020.140247

\section{Figure captions}

Fig. 1 - Temperature $\mathrm{x}$ time profiles registered at different points along the length of the casting during solidification of Al-10wt.\% Si-(Mg) alloys.

Fig. 2 - Scheil diagrams showing the solidification sequences related to the Al-10wt.\% Si- $0.45 \mathrm{wt} . \%$ $\mathrm{Mg}$ and $\mathrm{Al}-10 \mathrm{wt} . \% \mathrm{Si}-1 \mathrm{wt} . \% \mathrm{Mg}$ alloys.

Fig. 3 - Representations in color maps of the evolution of growth velocities and cooling rates from top to bottom along the lengths of the solidified Al-Si-Mg bodies.

Fig. 4 - Columnar-type grain morphology revealed along the longitudinal section of the evaluated AlSi-Mg castings.

Fig. 5 - Light microstructures showing dendritic arrangements and their dependencies with cooling rates and growth velocities for the $\mathrm{Al}-10 \mathrm{wt} . \% \mathrm{Si}-0.45 \mathrm{wt} . \% \mathrm{Mg}$ alloy. 
Fig. 6 - Light microstructures showing dendritic arrangements and their dependencies with cooling rates and growth velocities for the Al-10wt.\% Si-1wt.\% Mg alloy.

Fig. 7 - SEM images showing the formed phases, details with greater magnification and color mapping of the elements Al, Si and Mg: (a) Al-10 wt.\% Si-1 wt.\% Mg and (b) Al-10 wt.\% Si-0.45 wt.\% Mg.

Fig. 8 - Experimental variations of $\lambda_{1}$ and $\lambda_{2}$ against position from the metal-mold interface along the length of the Al-10 wt.\% Si-1wt.\% Mg and Al-10 wt.\% Si-0.45 wt.\% Mg alloys castings.

Fig. 9 - Scaling relations of microstructural spacings with thermal solidification parameters, such as cooling rate and growth velocity for the Al-Si(-Mg) alloys.

Fig. 10 - Tensile properties of the Al-10 wt.\% Si-1wt.\% Mg and Al-10 wt.\% Si-0.45 wt.\% Mg alloys as function of $\lambda_{1}$. 